Fanum

Sociológico
Forum Sociológico

Série II

17 | 2007

Envelhecimento activo. Um novo paradigma

\title{
Envelhecimento demográfico e alargamento do tempo de trabalho - O debate inacabado. Implicações socio-económicas e busca de novos paradigmas
}

Maria João Molina Vicente

\section{OpenEdition}

\section{Journals}

Edição electrónica

URL: https://journals.openedition.org/sociologico/1651

DOI: 10.4000/sociologico.1651

ISSN: 2182-7427

Editora

CICS.NOVA - Centro Interdisciplinar de Ciências Sociais da Universidade Nova de Lisboa

Edição impressa

Data de publição: 1 janeiro 2007

Paginação: 69-79

ISSN: 0872-8380

Refêrencia eletrónica

Maria João Molina Vicente, «Envelhecimento demográfico e alargamento do tempo de trabalho - 0 debate inacabado. Implicações socio-económicas e busca de novos paradigmas», Forum Sociológico [Online], 17 | 2007, posto online no dia 01 janeiro 2007, consultado o 29 março 2022. URL: http:// journals.openedition.org/sociologico/1651 ; DOI: https://doi.org/10.4000/sociologico.1651 


\title{
ENVELHECIMENTO DEMOGRÁFICO E ALARGAMENTO DO TEMPO DE TRABALHO - O DEBATE INACABADO. IMPLICAÇÕES SOCIO-ECONÓMICAS E BUSCA DE NOVOS PARADIGMAS
}

\author{
Maria João Molina Vicente \\ Mestre em Demografia pelo ISCTE (maria_joao_vicente@hotmail.com)
}

\begin{abstract}
Resumo
O fenómeno do envelhecimento dem ográfico, pelo seu carácter complexo e multifacetado, interpela governos e sociedade civil a agir colectivamente e de forma qualificada perante os desafios lançados por esta que é uma questão que assume um lugar central como vector de desenvolvimento.

Porque se manifesta de forma abrangente em todos os níveis da vivência em sociedade e porque tem importantes implicações na estruturação do tecido produtivo, o fenómeno do envelhecimento exige também um exame atento aos fundamentos de uma sociedade com uma maior abrangência de cidadania.

O escrutínio e regulação da actividade económica não podem por si só, como outrora, amortecer os efeitos adversos provenientes da globalização pelo que se torna necessária uma gestão mais efectiva dos riscos que the são inerentes por parte dos agentes sociais. Neste enquadramento, propomos uma reflexão acerca das possíveis soluções de mitigação dos impactos do envelhecimento populacional, nomeadamente, da população activa.
\end{abstract}

Palavras-chave: Desenvolvimento; Emprego; Envelhecimento; Protecção Social

\begin{abstract}
The complex and multifaceted nature of the demographic ageing phenomenon requires governments and citizens to act in a qualified way to face the challenges it poses, as a central development vector.

Because the effects of ageing are wide spread at all levels of social living and because of its implications in the productive tissue structure, ageing is a matter that requires an attentive analysis to the fundamentals of a society with a broader citizenship character.

The economic scrutiny and regulation are no longer enough when it comes to soften the globalization adverse effects. Therefore, a more effective management of globalization risks it to be met by all social actors. This is the frame within which we propose a debate on possible solutions in order to minimize the impacts of aging, namely, of the active population ageing.
\end{abstract}

Keywords: Development; Employment; Ageing; Social Protection.

\section{Introdução}

A consolidação de dinâmicas de mundialização das economias contribuiu para que a partir da década de 70 se acentuassem os mecanismos tendentes à reestruturação do mercado de trabalho e do emprego. A crescente competitividade e progressiva secundarização do factor trabalho no contexto dos sistemas produtivos, conduziu o mercado de trabalho a enfrentar alguns paradoxos ainda hoje não superados. Os fenómenos demográficos contribuíram para agudizar, ainda que silenciosamente, a necessidade de mudança de paradigma. As políticas públicas de gestão da actividade e da inactividade, reféns de uma certa rigidez institucional que caracteriza os países da Europa continental (Guillemard, 2002), nem sempre foram consequentes com a tendência para o envelhecimento demográfico que com eçou a desenhar-se mesmo antes da década de 70 .

Nessa altura ainda era recente o fenómeno baby boom e largos contingentes de baby boomers constituíam uma abundância de mão-de-obra suficiente para saturar o mercado de trabalho, levando à ponderação de políticas públicas restritivas da presença 
de força de trabalho mais velha. Só nos últimos anos, mercê da existência de dados estatísticos que permitem reconstituir situações passadas e avaliar evoluções demográficas recentes, projectando-as para o futuro, ficaram patentes alguns dos erros cometidos por uma política generalizada de fomento da inactividade.

A robustez dos sistemas de Welfare State nunca ficou porventura demonstrada e os efeitos das tendências demográficas recentes nas sociedades europeias não desmentem uma certa fragilidade de base. Pensou-se que o objectivo do pleno emprego atingir-se-ia no contexto de uma economia seguida atentamente pelos analistas e decisores políticos. Nesta acepção, a economia seria gerida de forma a garantir um acesso generalizado ao emprego e os sistemas de protecção social teriam condições para funcionar a partir do elevado número de contribuintes e da redução da prestação social de cobertura ao desemprego.

Na maior parte das sociedades, o valor do trabalho aparece ainda como um valor fundamental, por relação ao qual os indivíduos desenvolvem as suas competências de sociabilidade e de produção. A forma abrupta e precoce com que os indivíduos atingem a reforma torna esse momento crucial para quem se vê assim obrigado a repensar a sua inserção social e até a sua utilidade. Rosa Martins sublinha que "a sociedade moderna marginalizou 'os velhos' dando prioridade a valores ligados à produtividade, rentabilidade, consumo excessivo" (Martins, 2002). Na mesma linha de pensamento, a autora refere que,

"O trabalho especializado leva a uma estratificação e segregação etárias: os que aprendem, os que produzem e aqueles que saíram do ciclo produtivo, onde se incluem os idosos. (...) A pessoa idosa perde desta forma o seu papel de transmissor transgeracional do saber...". (Martins, 2002)

A perda do estatuto que tradicionalmente se atribuía às gerações mais velhas é, em grande parte vivenciada na família, verificando-se uma redefinição dos papéis de cada um dos seus membros, por referência aos novos padrões daquilo que é hoje tido como o maior dos activos - o conhecimento. $O$ conhecimento não é já apanágio dos mais velhos, mas sim daqueles que acumulam um espectro substancial de formação direccionada para a competição no mercado de trabalho - o conhecimento é hoje a forma de "saber" por excelência.

É neste contexto complexo e multifacetado que nos propomos reflectir sobre a problemática do envelhecimento e seus reflexos na organização socio-económica das sociedades ocidentais. A nossa análise será direccionada para os aspectos parti- culares de conflito que se projectam na dinâmica do mercado de trabalho e se voltam a projectar na vivência individual da inactividade desafiando o enquadramento institucional e familiar da sociedade contemporânea.

\section{Ciclo de vida, envelhecimento e representação social da velhice}

As sociedades dos países ditos desenvolvidos vivem actualmente um problema demográfico - o problema do envelhecimento. Esta afirmação aparece sustentada nas estatísticas que indicam que a taxa de natalidade da generalidade dos países ocidentais é cada vez mais baixa, realidade esta que se conjuga com uma taxa de mortalidade reduzida ${ }^{1}$. Com o advento da chamada transição demográfica moderna, as sociedades ocidentais passaram a registar crescimentos naturais bastante diminutos, estando em causa, nalguns países, a própria substituição de gerações, em que as descendências médias já se situam muito abaixo dos 2,1 filhos por mulher.

Esta evidência empírica traduz um fenómeno relativamente novo com importantes implicações ao nível das pirâmides etárias. O número de efectivos populacionais com 65 anos e mais tem vindo a aumentar de forma sustentada e nas idades mais jovens é patente o desgaste da pirâmide. Tal significa que o rácio entre jovens e velhos tende a diminuir, havendo cada vez menos indivíduos com idade até 15 anos por cada indivíduo com 65 anos e mais e, em alguns países, este último grupo já ultrapassou o dos mais jovens. O envelhecimento demográfico é, nesta acepção, uma realidade que se manifesta numa acentuada erosão das pirâmides etárias na base e um simultâneo alargamento dos efectivos no topo, por adiamento progressivo da idade de morrer dos indivíduos.

Este adiamento do calendário de morte torna visível um outro efeito com manifestações distintas em cada pessoa - o da velhice. A velhice é algo que ocorre com qualquer ser humano (e animal) porque se trata de um fenómeno biológico que é particularmente patente a partir de certa idade. Por seu turno, o envelhecimento decorre de forma contínua e sistemática desde o início do ciclo de vida de qualquer ser vivo.

Parece-nos oportuno sublinhar a ideia que aponta para o facto de que a velhice se manifesta de forma diferente de indivíduo para indivíduo em função dos percursos pessoais e espaço social de inserção. Não sendo essa idade da velhice especificável, duas pessoas com a mesma idade podem apresentar sinais distintos de velhice; basta para tanto que os seus organismos reajam de formas diferentes ao desgaste do tempo. A este propósito refira-se ainda o conceito de itinerários que surge 
na literatura para caracterizar percursos de vida que induzem situações de velhice diferenciadas e comprometem generalizações do conceito (Fernandes, 1999).

Assim, ainda que a OMS identifique o acentuar do processo de envelhecimento individual a partir dos 65 anos nos países ricos e a partir dos 60 anos nos países em desenvolvimento, parece evidente que este, mesmo reportando-se a uma faixa etária determinada, tem as suas especificidades marcadas pela posição social de classe, pela cultura e pelas condições socioeconómicas e sanitárias individuais e/ou colectivas do contexto de inserção dos indivíduos.

\section{Velhice e reforma}

Velhice e reforma são dois conceitos que se justapõem na consciência colectiva das sociedades modernas. A velhice traduz-se num fenómeno irreversível e com diferentes manifestações individuais, manifestações essas que tendem a afastar os mais velhos da esfera produtiva. Os valores de referência da cultura de "classe trabalhadora" parecem continuar a dar sentido às vivências dos mais velhos, lançando interrogações relativamente ao fenómeno de saída precoce do mercado de trabalho de indivíduos ainda capazes de desempenhar as suas funções enquanto agentes produtivos. A tendência dominante parece ser aquela que foi ditada pelas

\footnotetext{
"(...) políticas sociais de velhice [que] acentuaram as clivagens entre Jovens e Velhos, Activos e Inactivos e contribuíram para segregar para espaços sociais restritos, indivíduos potencialmente válidos." (Fernandes, 2003)
}

Neste sentido, ganha substrato a noção de que o afastam ento precoce do mercado de trabalho favorece a ocorrência de uma aposentadoria de dupla vertente. Por um lado, a reforma por tempo de serviço, e uma segunda "reforma", nem sempre com reconhecimento oficial, mas determinada pelos limites impostos pelo corpo e pelo processo de exclusão do mundo do trabalho.

Com o aumento da longevidade, o período de vida global é ampliado mas estende-se também o número de anos em que os indivíduos se encontram afastados do mundo do trabalho e da actividade produtiva em geral. A maior longevidade das populações encerra um importante paradoxo - o da não coincidência entre velhice, na sua vertente de debilidade física e diminuição da capacidade produtiva, e idade de reforma, a qual ocorre cada vez mais cedo em relação ao período em que irão efectivamente começar a manifestar-se de forma indelével os efeitos da idade sobre a capacidade de trabalho do indivíduo.
Os percursos individuais são cada vez mais exigentes do ponto de vista da multiplicidade de escolhas e caminhos relativamente aos quais há que optar. Nas sociedades tradicionais os percursos individuais eram tendencialmente lineares. A cada membro da família cabia desempenhar um papel definido e relativamente inflexível. Os indivíduos sabiam, em cada idade da vida, o que deles se esperava. As sociedades modernas estão estruturadas em torno de uma organização familiar distinta que privilegia a formação e o saber como forma de mobilidade social (Gaullier, 2002). Num mundo crescentemente globalizado, as formas de saber são inúmeras e o estatuto individual de cada membro da família pode ser atingido de diversas formas. A idade assume-se como um factor concorrencial por referência às realizações atingidas em cada momento da vida. Novas formas de conviviabilidade entre gerações ganham expressão a partir dos contextos individuais e familiares multifacetados. Este fenómeno contribui para que se avolume a necessidade de mudança de representações e práticas nomeadamente no que diz respeito à inactividade.

\section{Novas formas de conviviabilidade intergeracional e tendências de mudança}

No espaço social vivenciado pela maioria de nós, proliferam as imagens de exaltação da juventude como fonte de saúde e progresso. Neste contexto, os velhos são o anti-modelo. Eternizam-se os pruridos relativamente às designações - terceira idade, idosos, velhos - os diversos países europeus adoptam uma ou outra designação em função do grau de formalismo do seu registo institucional.

Os percursos de vida em permanente mudança geram oportunidades diferenciadas de partilha de experiências entre gerações. Com o alargamento da esperança de vida, é cada vez maior o espectro de gerações que coexiste. Mas a convivência entre elas não está isenta de constrangimentos e a institucionalização dos idosos tende a surgir como uma alternativa à progressiva saturação do modelo familiar dito tradicional. As novas formas de conviviabilidade engendradas pela sociedade pós industrial segregam os mais velhos comprometendo a sua qualidade de vida nos anos suplementares conquistados pelos avanços da medicina.

É na fam ília que esta instabilidade tem que ser gerida em primeira instância. Pensar os problemas do envelhecimento implica atender às estruturas familiares e à sua capacidade de suporte aos idosos, actualmente e no futuro. Este suporte é feito tanto pela via formal ou institucionalizada como pela via informal configurada pelas redes de suporte tradicionais. O suporte prático e afectivo aos idosos faz-se essencialmente através do cônjuge, sendo que as mulheres, com maior longevidade do que os 
homens, têm maior probabilidade de se defrontar com situações de solidão. Mesmo enquanto ainda existe mais do que um filho no casal, nem sempre os irmãos conseguem articular-se para prestar a ajuda necessária, subsistindo situações mais ou menos diferenciadas de abandono ou carência material e afectiva.

A vivência actual induz o isolamento individual ao mesmo tempo que amplifica as formas não presenciais de convívio e partilha, tecendo um espaço social progressivamente virtual. O ambiente de troca e comunhão associado ao arquétipo da família alargada extingue-se, ao mesmo tempo que os conflitos e gestão das dificuldades dessa conviviabilidade se desenrolam noutro cenário - o do progressivo individualismo dos percursos pessoais de cada um dos elementos da família (Burtless, 2000).

A relação entre pais e filhos alterou-se e domina algum paradoxo - por um lado, fala-se de uma maior cumplicidade baseada em relações de proximidade menos formalizadas na hierarquia familiar, por outro lado, também é verdade que pais e filhos se encontram relativamente incomunicantes. Não existem porventura muitos estudos que trabalhem este paradoxo, mas a percepção que temos é a de que continua a existir um certo afastamento entre as gerações. Se há duas ou três décadas o casamento era um instrumento privilegiando de libertação em relação aos pais, hoje, o facto de os jovens saírem de casa cada vez mais tarde parece estar mais ligado à precariedade de emprego nos primeiros anos de actividade e à incerteza dos anos subsequentes do que à vontade manifesta em permanecer junto dos pais.

Neste cenário, não parece previsível um aumento substantivo das relações de solidariedade entre as gerações mais novas e as mais velhas, permanecendo o dilema da insuficiência das redes de suporte natural insuperado. Isto é, não é claro como é que no futuro estas redes podem vir a amplificar-se, mercê de uma maior disponibilidade financeira ou até afectiva das gerações mais novas. É neste contexto que nos parece oportuno introduzir a noção de que é desejável que se crie uma progressiva autonomia dos mais velhos, a qual possa induzir formas de participação social mais efectivas. Para este desiderato concorrem factores de natureza individual e institucional - é importante estimular a capacidade dos indivíduos e instituições prepararem um processo progressivo de transição para a reforma.

\section{Saúde e protecção social}

A saúde é um bem que se constitui como um activo individual e colectivo e que potencia o acesso às diversas formas de cidadania, entre elas, a capacidade de trabalho. A ausência deste bem pode interferir nas formas de conviviabilidade intergeracional por via da degradação da pessoa humana em consequência das doenças de degenerescência, por exemplo. O suporte familiar é frequentemente frágil em face destas circunstâncias e hoje é patente que a família não pode suportar, por si só, os riscos da velhice. As estruturas familiares não têm condições de suportar todos os riscos de doença associados a uma esperança de vida cada vez mais alargada. Por outro lado, o Estado enfrenta crescentes dificuldades para assegurar de forma indiferenciada a todos os cidadãos a saúde na fase da vida em que estes mais precisam de recorrer aos sistemas nacionais de saúde. Muito se tem discutido relativamente ao papel do associativismo na superação destas carências mas, em sociedades crescentemente urbanizadas, a implem entação de esquemas de entreajuda no seio da sociedade civil permanece um desafio.

Um esquema de protecção social que possa cobrir virtualmente todos os riscos da existência humana teria que ser extremamente eficiente e dispor de recursos quase ilimitados. A existir, tal esquema só poderia estar fundado num modelo muito sofisticado de crescimento e desenvolvimento económico. O próprio desenvolvimento é refém das franjas de exclusão e marginalização que cria. Neste contexto, permanece a busca de um círculo virtuoso de desenvolvimento havendo em primeira instância que fortalecer os mecanismos de absorção dos impactos sociais do crescimento económico, se aceitarmos que sem este não há desenvolvimento. A via parece ser a da prevenção de certos riscos da existência humana e o combate às formas de exclusão mais prementes, como aquelas que são frequentemente enfrentadas por quem experimenta uma velhice precoce induzida pelo afastamento antecipado do espaço social de referência por excelência, o mundo do trabalho.

\section{O debate inacabado do alargamento do tempo de trabalho - implicações socio-económicas e busca de novos paradigmas}

Quanto tempo é razoável pensar que os mais velhos podem permanecer no mercado de trabalho com um risco limitado de marginalização profissional? Esta é uma questão que parece estar em aberto. A problemática do alargamento do tempo de trabaIho como forma de promover uma maior eficiência socio-económica, mais satisfatória em termos das relações de forças que se estabelecem entre o mercado de trabalho e os esquemas de protecção social, permanece e encontra-se enquadrada por um leque de soluções e caminhos de consequências nem sempre inequívocas.

A ampliação da concorrência nas sociedades ocidentais mercê da intensificação de uma economia 
de mercado cada vez mais aberta, globalizada e dinâmica levou a que profundas alterações estruturais tivessem lugar no tecido sócio económico dos países ocidentais. A crise económica do final dos anos 70 despoletou a decadência do contrato social baseado na organização da vida em três etapas - formação, produção e reforma, alterando a linearidade dos comportamentos e até dos valores (Gaullier, 1996). A um padrão relativamente homogéneo de actuação por parte dos agentes económicos e dos actores sociais sucedeu-se uma multiplicidade de novas formas de posicionamento na profissão e na vida pessoal. A previsibilidade de comportamentos esbateu-se, complexificando-se as relações sociais e económicas.

A competitividade gerou o dilema da mão-de- obra excedentária o que precipitou o incentivo a medidas de redução do tempo de trabalho, como forma de protecção do emprego e como meio de preservar os salários dos indivíduos em plena idade activa (Gaullier, 2002). A pré-reforma passou a ser vista como uma solução para muitos dos problemas causados pelo advento da globalização no mercado de trabalho.

As empresas viam neste expediente uma forma de baixar a média de idades dos seus efectivos e reduzir pessoal num contexto de mecanização progressiva de certas tarefas rotineiras. Socialmente, a reforma antecipada garantia estatuto a quem a ela tinha acesso uma vez que granjeava um período longo de inactividade, em que seria possível desenvolver um projecto individual dedicado ao próprio e ao lazer. A evolução social ditou no entanto que o sistema de pré reformas se revelasse insustentável, tanto pelo potencial de subaproveitamento da força de trabalho como pela diminuição meramente administrativa da média de idades sem que houvesse recrutamentos de forma a dar lugar também aos mais jovens (Guillemard, 2002).

Durante os anos 90 os discursos sobre o enveIhecim ento enfatizaram a necessidade de prolongar o tempo de actividade em face da evidência de períodos de inactividade pensionados cada vez mais alargados e, por consequência, insustentáveis. O mecanismo de incentivo às reformas antecipadas foi posto em causa pela progressiva incapacidade dos sistemas de protecção social garantirem níveis de reforma compatíveis com o salário bruto auferido durante o período de actividade e em virtude da agitação social causada pela expectativa de reforma dos activos em idades vizinhas da idade de pré reforma (Gaullier, 1996).

Embora estejamos longe da aplicabilidade plena, ou quase plena, das regras da concorrência perfeita, verifica-se uma crescente subordinação dos agentes aos mecanismos de funcionamento liberal dos mercados. A nível empresarial, cada vez menos as empresas com baixa produtividade e reduzida capacidade de adaptação e inovação terão condições de sobreviver. Também na componente laboral, a mão-de-obra sub qualificada terá dificuldades em competir com a mão-de- obra que reuniu competências e saberes ao longo da vida.

Identificamos aqui um potencial de desfragmentação social de acordo com o qual poderão emergir novas formas de exclusão fomentadas pelo não acesso à formação ao longo da vida. Essa marginalização prejudicará mais aqueles que reúnem simultaneamente duas condições - ausência de qualificações actualizadas e relativamente menos tempo de actividade para as adquirir.

Os modelos de protecção social vigentes tiveram o seu surgimento fundado em condições particulares de compatibilidade entre o desenvolvimento económico da época em que se generalizaram e as características demográficas desse mesmo contexto, adequando-se à repartição das idades da vida em três momentos (Fernandes, 1999). Os riscos acrescidos a que estão hoje sujeitos os indivíduos nos seus percursos individuais relativamente heterogéneos configuram, em nosso entender, um potencial problema no que diz respeito a possíveis novas formas de marginalização social. É verdade que a incapacidade para o trabalho poderá manifestar-se cada vez mais tarde num contexto de alargamento da esperança de vida, no entanto, isso, só por si, não garante a permanência no mercado de trabalho em condições de adaptação às exigências da vida profissional moderna. A flexibilidade de funções e papéis em consonância com a idade dos indivíduos é ainda um objectivo, mais do que uma realidade.

A temática do emprego (e desemprego) continua a fazer emergir algumas controvérsias sobre a necessidade de repensar o Estado Providência. As dificuldades de acesso ao emprego e as situações de desemprego com características crescentemente difusas concorrem para que os países da Europa continental tenham fomentado nos últimos 30 anos a saída precoce do mercado de trabalho, provocando uma "espiral de inactividade" (Guillemard, 2002) com repercussões socio-económicas de âmbito alargado.

A erosão de competências provocada pelo advento da mecanização do trabalho e generalização da competitividade induziu a uma rápida obsoletização da mão-de-obra mais velha (Burtless, 2000). Paralelamente, assistiu-se a uma baixa generalizada do emprego em todas as idades, destacando-se as dificuldades de (re)acesso ao emprego por parte da força de trabalho fragilizada por situações de desemprego cada vez mais duradouras. Os sistemas de protecção social têm vindo a evoluir para uma situação de cobertura de, virtualmente, todos os riscos da existência, mas a questão do desemprego continua a ser fracturante nas sociedades europeias. 
De acordo com Anne Marie Guillemard, os mais velhos têm um estatuto privilegiado nos seus empregos pois estão seguros no seu posto de trabalho enquanto que se assiste a uma exclusão em massa dos mais novos do mercado de trabalho. $O$ encorajamento da inactividade e as opções tomadas que justificaram as reformas antecipadas dos indivíduos entre os 50 e os 55 anos e entre 60 e 65 anos, conduziram a uma cada vez mais aguda certeza de que o equilíbrio financeiro dos sistemas se encontra em causa.

Mas a retirada massiva da oferta de mão-de-obra com mais dificuldades de acesso ao emprego promovida nas últimas décadas não resolveu o problema do desemprego. A indemnização do não trabalho dos mais velhos (Guillemard, 2002), leva alguns autores a falar do "fim do trabalho"(Rifkin, 1997). Trata-se de uma ideia sugestiva se pensarmos na progressiva tercearização e sofisticação das actividades económicas e consequente substituição da força de trabalho pela tecnologia.

Tal como já referimos, o uso massivo do expediente da saída precoce do mercado de trabalho, iludiu os agentes económicos relativam ente à necessidade de adaptação às novas exigências do mercado (Aglietta, 2002). O imperativo da produtividade e da (re)valorização profissional permaneceu oculto e a sua implem entação adiada. Em nosso entender, mantém-se a necessidade aguda de promover o aum ento da produtividade em termos globais como forma de gerar riqueza e proceder à sua redistribuição, minorando os diversos focos de exclusão que o crescimento económico induz.

As tendências de mudança que se desenharam nas últimas décadas, consagraram o trabalho enquanto fonte de realização pessoal e elo de ligação a toda a dinâmica sócio produtiva (Burtless, 2000). Não obstante, no contexto actual do envelhecimento demográfico, parece-nos impossível ignorar potenciais problemas decorrentes desta situação. Como vão os mais velhos adaptar-se às exigências do mercado de trabalho em que até os mais novos têm dificuldade em competir? Como vão eles gerir a sua passagem à inactividade? Somos (re)conduzidos à noção de que a busca de novos paradigmas permanece em aberto.

\section{Notas Finais}

O envelhecimento demográfico é um problema que ganha visibilidade no discurso político e nos diversos fóruns relacionados com os desafios actuais, mas os seus contornos e implicações permanecem em parte descaracterizados, não havendo soluções claram ente definidas para problemas identificados. Os indicadores de envelhecimento demográfico da generalidade dos países europeus apontam sistematicamente para o aumento da proporção de indivíduos com mais de 65 anos e, em paralelo, para a redução da proporção de jovens (entre os zero e os 14 anos). A esperança de vida tem vindo a registar importantes ganhos principalmente ao nível das probabilidades de sobrevivência a partir dos 65 anos, verificando-se um concomitante alargamento do tem po de inactividade. O desequilíbrio intergeracional aparece como uma característica demográfica bem marcada da população europeia, acentuando-se os traços de um envelhecimento que parece irreversível à luz da evidência empírica actual.

Mercê da crescente notoriedade do fenómeno do envelhecimento demográfico, avoluma-se o debate conceptual que remete para as categorias sociais de velhice, de reforma e de inactividade. Agudiza-se igualmente a necessidade de repensar a organização da vida social, económica e familiar em função da alteração do paradigma produtivo estruturado em torno do conhecimento e do saber. As repercussões a nível da esfera individual e familiar são difusas. O paradoxo do aumento da idade da velhice e redução da idade da reforma que tem predominado nos últimos anos, revela-se insustentável no futuro e a inflexibilidade estrutural das instituições não tem contribuído para operar os necessários reajustamentos. Tal inflexibilidade, e mesmo relutância à mudança, é acentuada pela questão dos direitos adquiridos que têm que ser geridos de forma cuidadosa, sob pena de se gorarem colectivamente as expectativas depositadas no Welfare State do pós-guerra.

$\mathrm{Na}$ análise dos problemas relacionados com o envelhecimento demográfico vimos que emergem conceitos ligados à valorização social do trabalho, à redução do tempo de actividade e produção, mas surge também a questão dos percursos individuais. São estes que, em última análise, favorecem uma maior ou menor exposição aos riscos da existência humana. Como se manifestam de forma difusa estes devem ser partilhados, isto é, no seio da sociedade civil devem ser criados mecanismos de apoio e suporte social consistentes. Esta parece ser uma via privilegiada de prevenção do "recuo civilizacional" (Fernandes, 1999) que pode advir de se deixar entregue ao mercado o arbítrio de todos riscos.

Para assegurar o equilíbrio dos sistemas de protecção social, depositam-se esperanças no aum ento da idade da reforma à medida que se registam ganhos na esperança de vida e procura-se evitar que os ganhos de produtividade sejam reflectidos no imediato no aumento das pensões. Simultaneamente, defende-se o ajustam ento das contribuições para o sistema, preconizando-se o reposicionamento do Estado perante estas questões, invocando-se a reinvenção do seu carácter regulador, nomeadamente promovendo a superação das barreiras institucionais e de resistência à mudança. 


\section{Referencias bibliográficas}

AGLIETTA, M., D. Blanchet e F. Héran (2002), Démographie et économie, Rapport du Conseil d'Analyse Economique N.ㅇ 38, Paris, La Documentation Française.

BURTLESS, G. e J. F. Quinn (2000), Is working longer the answer for an ageing workforce?, Working Paper 550, Centre for Retirement Research, Boston, Boston College.

ESPING-ANDERSEN, G. (ed.) (1996), Welfare states in transition: national adaptations in global economies, London, Sage Publications.

FERNANDES, A. A. (1999), "Reforma, velhice e cidadania: dúvidas e certezas de um contrato social", Cadernos de Política Social, 2-3, pp. 9-28.

FERNANDES, A. A. (2003), "Do Envelhecimento demográfico às políticas públicas de protecção social", in Portela, J. e J.C. Caldas (org.), Portugal Chão, Oeiras, Celta Editores, pp. 87-110.

GAULLIER, X. (1996), "La Mutation des âges", in P. Bourdelais, X. Gaullier et M.-J. Imbault-Huart, État-providence, arguments pour une réforme, Paris, Gallimard.
GAULLIER, X. (2002), "Emploi, retraites et cycles de vie", Retraite et société, 2002/3 (37), pp. 163-207.

GUILLEMARD, A. M. (2000), Aging and the Welfare State Crisis, Cranbury/New Jersey, Associated United Presses.

GUI LLEMARD, A. M. (2002), "L'Europe continentale face à la retraite anticipée: barrières institutionnelles et innovations en matière de reforme", Revue Française de Sociologie, 43 (2), pp. 333-368.

JACOB, J. (2001), A Velhice, Dissertação de Mestrado, Lisboa, ISCTE.

MARTINS, R. (2002), "Envelhecimento demográfico", Milenium - Revista do Instituto Superior Politécnico de Viseu, 26, http://www.ipv.pt/millenium.

RIFKIN, J. (1997), La Fin du travail, Paris: La Décoverte.

RODRIGUES, P. (2002), Social security in Portugal: an update of long-term projections, Working Paper n. 27, Lisboa: DGEP.

\section{Endereços electrónicos}

http://epp.eurostat.ec.europa.eu/

http://www.un.org.com

http://www.ine.pt

\section{ANEHOS}

Quadro $1 \triangleright$ Taxa Bruta de Natalidade (permilagem)

\begin{tabular}{|l|c|c|c|c|c|c|}
\hline & 1960 & 1970 & 1980 & 1990 & 2000 & 2004 \\
\hline Alemanha & 17,3 & 13,4 & 11,1 & 11,4 & 9,3 & 8,6 \\
\hline Áustria & 17,9 & 15,0 & 12,0 & 11,8 & 9,8 & 9,7 \\
\hline Bélgica & 16,9 & 14,7 & 12,6 & 12,4 & 11,3 & 11,1 \\
\hline Chipre & 26,5 & 19,2 & 20,3 & 18,3 & 12,2 & 11,2 \\
\hline Dinamarca & 16,6 & 14,4 & 11,2 & 12,3 & 12,6 & 12,0 \\
\hline Eslováquia & - & - & - & - & - & - \\
\hline Eslovénia & 17,5 & 15,9 & 15,7 & 11,2 & 9,1 & 9,0 \\
\hline Espanha & 21,7 & 19,6 & 15,3 & 10,3 & 9,9 & 10,6 \\
\hline Estónia & 16,6 & 15,9 & 15,0 & 14,2 & 9,5 & 10,4 \\
\hline Finlândia & 18,5 & 14,0 & 13,2 & 13,1 & 11,0 & 11,0 \\
\hline França & 17,9 & 16,7 & 14,9 & 13,4 & 13,1 & 12,7 \\
\hline Grécia & 18,9 & 16,5 & 15,4 & 10,1 & 9,5 & 9,4 \\
\hline Holanda & 20,8 & 18,3 & 12,8 & 13,2 & 13,0 & 11,9 \\
\hline Hungria & 14,7 & 14,7 & 13,9 & 12,1 & 9,6 & 9,4 \\
\hline Irlanda & 21,5 & 21,8 & 21,7 & 15,1 & 14,4 & 15,2 \\
\hline Itália & 18,4 & 16,7 & 11,3 & 10,0 & 9,5 & 9,7 \\
\hline Letónia & 16,7 & 14,5 & 14,1 & 14,2 & 8,5 & 8,8 \\
\hline Lituânia & 22,5 & 17,7 & 15,2 & 15,4 & 9,8 & 8,9 \\
\hline Luxemburgo & 15,9 & 13,0 & 11,5 & 12,8 & 13,1 & 12,0 \\
\hline Malta & 26,3 & 17,5 & 17,3 & 15,2 & 11,0 & 9,7 \\
\hline Polónia & 22,6 & 16,8 & 19,6 & 14,4 & 9,8 & 9,3 \\
\hline Portugal & 24,1 & 20,8 & 16,2 & 11,7 & 11,7 & 10,4 \\
\hline Reino Unido & 17,5 & 16,2 & 13,4 & 13,9 & 11,5 & 12,0 \\
\hline Rep. Checa & 13,4 & 15,0 & 14,9 & 12,6 & 8,8 & 9,6 \\
\hline Suécia & 13,7 & 13,7 & 11,7 & 14,5 & 10,2 & 11,2 \\
\hline UE 15 & 18,3 & 16,1 & 13,0 & 12,0 & 10,8 & 10,7 \\
\hline UE 25 & 18,5 & 16,1 & 13,8 & 12,3 & 10,6 & 10,5 \\
\hline Fonte: & & & & & \\
\hline
\end{tabular}

Fonte: EUROSTAT, Estatísticas Demográficas 
Quadro $2 \triangleright$ Taxa Bruta de Mortalidade (permilagem)

\begin{tabular}{|c|c|c|c|c|c|c|}
\hline & 1960 & 1970 & 1980 & 1990 & 2000 & 2004 \\
\hline Alemanha & 12,0 & 12,5 & 12,2 & 11,6 & 10,2 & 9,9 \\
\hline Áustria & 12,7 & 13,2 & 12,2 & 10,8 & 9,6 & 9,1 \\
\hline Bélgica & 12,3 & 12,3 & 11,5 & 10,4 & 10,2 & 9,8 \\
\hline Chipre & 10,8 & 9,8 & 11,1 & 9,8 & 7,8 & 7,0 \\
\hline Dinamarca & 9,5 & 9,8 & 10,9 & 11,8 & 10,9 & 10,3 \\
\hline Eslováquia & - & - & - & - & - & - \\
\hline Eslovénia & 9,5 & 10,1 & 9,9 & 9,3 & 9,4 & 9,3 \\
\hline Espanha & 8,6 & 8,3 & 7,7 & 8,6 & 9,0 & 8,7 \\
\hline Estónia & 10,4 & 11,2 & 12,3 & 12,4 & 13,4 & 13,2 \\
\hline Finlândia & 9,0 & 9,6 & 9,3 & 10,0 & 9,5 & 9,1 \\
\hline França & 11,4 & 10,7 & 10,2 & 9,3 & 9,0 & 8,4 \\
\hline Grécia & 7,3 & 8,4 & 9,1 & 9,3 & 9,6 & 9,4 \\
\hline Holanda & 7,6 & 8,4 & 8,1 & 8,6 & 8,8 & 8,4 \\
\hline Hungria & 10,2 & 11,6 & 13,6 & 14,0 & 13,3 & 13,1 \\
\hline Irlanda & 11,6 & 11,4 & 9,8 & 8,9 & 8,2 & 6,9 \\
\hline Itália & 9,6 & 9,7 & 9,8 & 9,6 & 9,8 & 9,4 \\
\hline Letónia & 10,0 & 11,2 & 12,8 & 13,1 & 13,6 & 13,8 \\
\hline Lituânia & 7,8 & 8,9 & 10,5 & 10,8 & 11,1 & 12,0 \\
\hline Luxemburgo & 11,8 & 12,4 & 11,3 & 10,0 & 8,7 & 7,9 \\
\hline Malta & 8,6 & 10,2 & 9,9 & 7,6 & 7,8 & 7,2 \\
\hline Polónia & 7,6 & 8,2 & 9,8 & 10,2 & 9,6 & 9,5 \\
\hline Portugal & 10,7 & 10,7 & 9,7 & 10,3 & 10,3 & 9,7 \\
\hline Reino Unido & 11,5 & 11,8 & 11,7 & 11,2 & 10,3 & 9,7 \\
\hline Rep. Checa & 9,8 & 12,5 & 13,1 & 12,5 & 10,6 & 10,5 \\
\hline Suécia & 10,0 & 9,9 & 11,0 & 11,1 & 10,5 & 10,1 \\
\hline UE 15 & 10,7 & 10,8 & 10,5 & 10,2 & 9,7 & 9,3 \\
\hline UE 25 & 10,4 & 10,6 & 10,6 & 10,4 & 9,9 & 9,5 \\
\hline
\end{tabular}

Fonte: EUROSTAT, Estatísticas Demográficas

Quadro $3 \triangleright$ Taxa de crescimento anual da população - \%

\begin{tabular}{|c|c|c|c|c|c|c|}
\hline & 1965 & 1970 & 1980 & 1990 & 2000 & 2004 \\
\hline Alemanha & 4,20 & 3,54 & 0,14 & 0,92 & 0,15 & $-0,01$ \\
\hline Áustria & 3,10 & 2,86 & $-0,09$ & 0,67 & 0,24 & 0,47 \\
\hline Bélgica & 3,28 & 2,46 & 0,13 & 0,20 & 0,24 & 0,39 \\
\hline Chipre & 2,80 & 4,08 & 0,79 & 1,78 & 1,17 & 2,10 \\
\hline Dinam arca & 3,83 & 3,50 & 0,20 & 0,10 & 0,30 & 0,26 \\
\hline Eslováquia & - & - & - & - & - & - \\
\hline Eslovénia & 3,61 & 4,88 & 1,12 & 0,00 & 0,51 & 0,05 \\
\hline Espanha & 4,78 & 5,70 & 0,74 & 0,18 & 0,62 & 1,63 \\
\hline EUA & 7,52 & 5,53 & - & 1,13 & 1,11 & 0,98 \\
\hline Estónia & 6,29 & 5,53 & 0,48 & 0,32 & $-0,51$ & $-0,37$ \\
\hline Finlândia & 3,29 & 1,23 & 0,27 & 0,40 & 0,21 & 0,27 \\
\hline França & 6,81 & 4,05 & 0,47 & 0,55 & 0,51 & 0,57 \\
\hline Grécia & 2,71 & 3,00 & 0,76 & 0,63 & 0,40 & 0,32 \\
\hline Holanda & 6,96 & 6,11 & 0,75 & 0,59 & 0,66 & 0,40 \\
\hline Hungria & 1,76 & 1,84 & 0,22 & $-0,44$ & $-0,30$ & $-0,25$ \\
\hline Irlanda & 1,30 & 2,44 & 1,13 & $-0,23$ & 1,23 & 1,61 \\
\hline Itália & 3,76 & 3,43 & 0,25 & 0,08 & 0,03 & 0,99 \\
\hline Japão & 5,08 & 4,89 & - & 0,34 & 0,18 & 0,05 \\
\hline Letónia & 7,18 & 4,30 & 0,24 & 0,04 & $-0,71$ & $-0,56$ \\
\hline Lituânia & 7,18 & 5,59 & 0,35 & 0,52 & $-0,68$ & $-0,49$ \\
\hline Luxemburgo & 5,43 & 2,73 & 0,55 & 1,07 & 1,64 & 0,89 \\
\hline Malta & $-1,83$ & $-5,61$ & 1,25 & 0,86 & 0,26 & 0,76 \\
\hline Polónia & 6,31 & 4,25 & 0,95 & 0,40 & $-0,03$ & $-0,07$ \\
\hline Portugal & 2,30 & $-3,67$ & 1,09 & $-0,18$ & 0,45 & 0,64 \\
\hline Reino Unido & 3,85 & 2,54 & 0,14 & 0,28 & 0,35 & 0,44 \\
\hline Rep. Checa & 1,22 & 1,55 & 0,46 & 0,02 & $-0,12$ & 0,09 \\
\hline Suécia & 3,00 & 4,02 & 0,23 & 0,80 & 0,08 & 0,39 \\
\hline UE 15 & 4,39 & 3,45 & 0,34 & 0,44 & 0,33 & 0,58 \\
\hline UE 25 & 4,47 & 3,46 & 0,41 & 0,41 & 0,25 & 0,48 \\
\hline
\end{tabular}

Fonte: EUROSTAT, Estatísticas Demográficas 
Gráfico $1 \triangleright$ Pirâmide Etária de Portugal em 1950, 2005 e 2050 de acordo as projecções das Nações Unidas de 2004, considerando o cenário médio

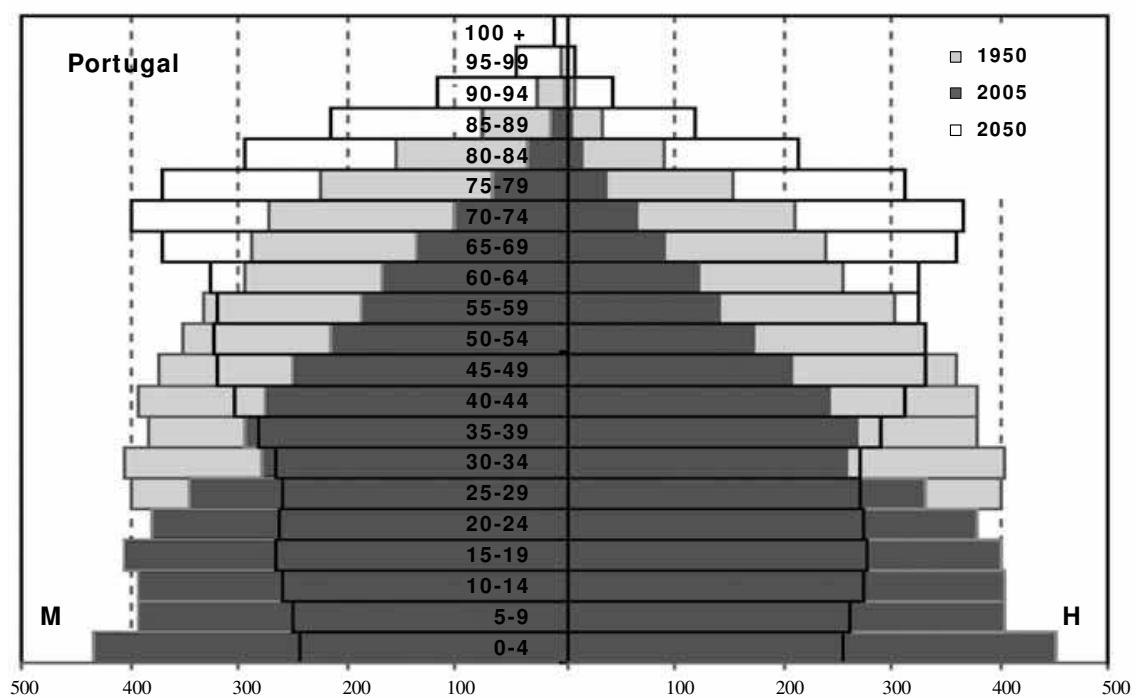

Fonte: Nações Unidas, Projecções Demográficas 2004

Gráfico $2 \triangleright$ Evolução dos rácios de dependência de jovens e idosos em Portugal e na UE 25, entre 1960 e 2004

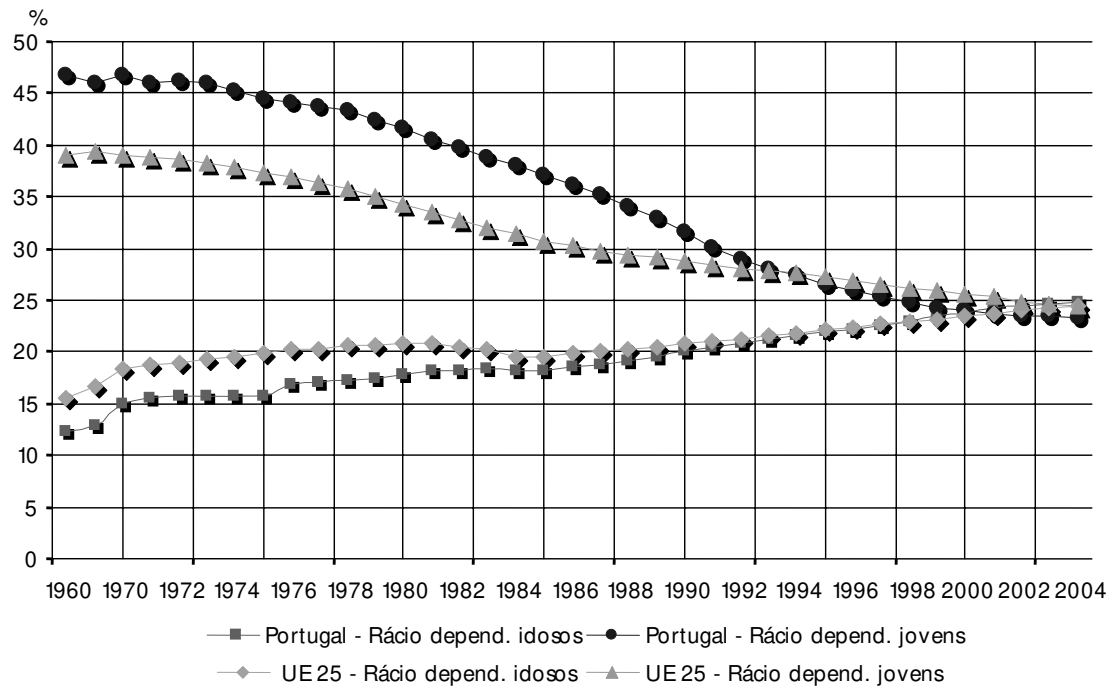

Fonte: EUROSTAT, Estatísticas Demográficas 
Gráfico $3 \triangleright$ Evolução dos rácios de dependência de jovens e idosos em Portugal e na UE 25, entre 1960 e 2004

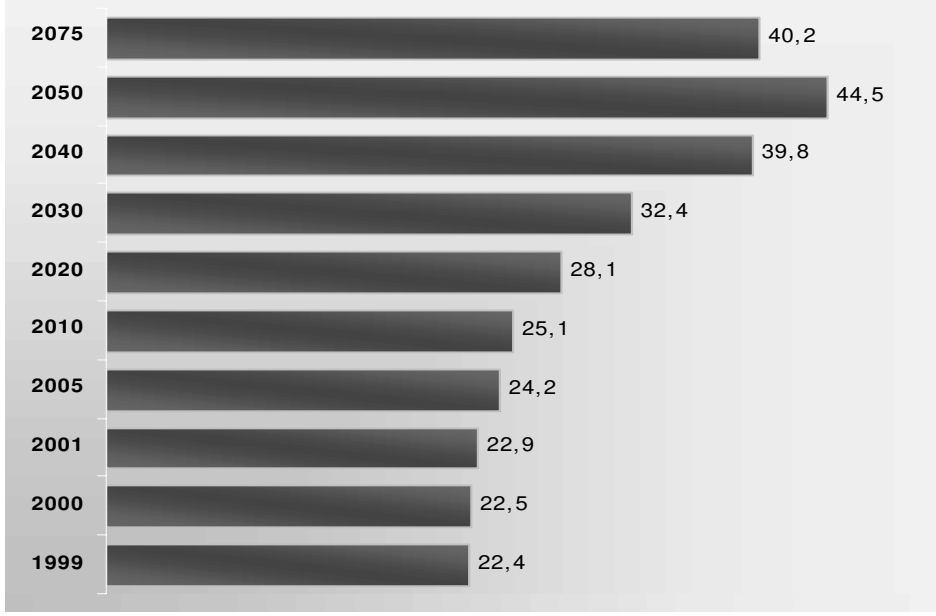

Fonte: DGEP - "Social Security in Portugal, An Update on long term projections"

Gráfico $4 \triangleright$ Peso das pensões de reforma em percentagem do PIB, em Portugal

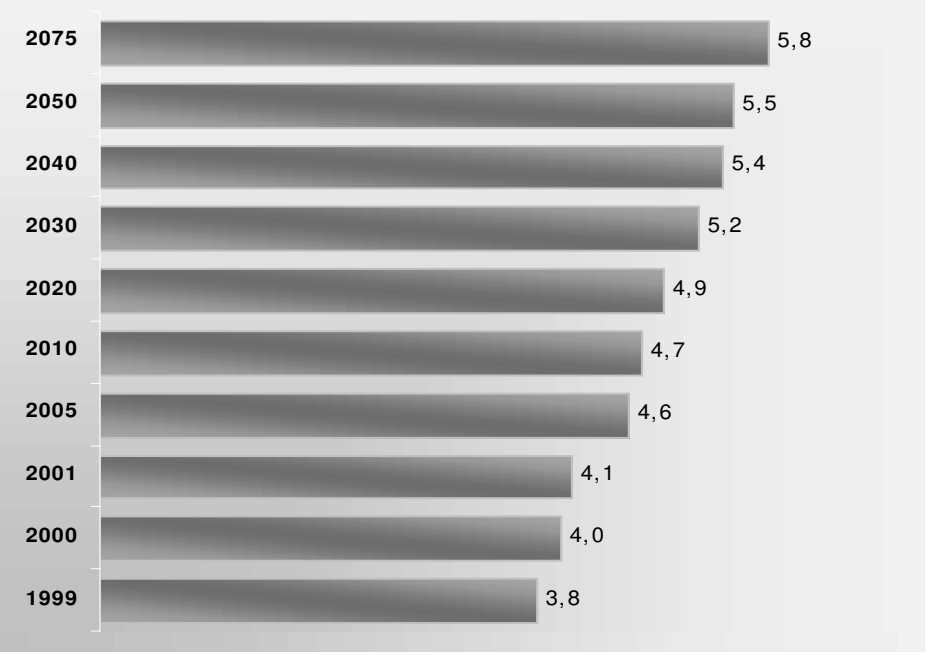

Fonte: DGEP - "Social Security in Portugal, An Update on long term projections" 
Gráfico $5 \triangleright$ Despesa média, em percentagem do PIB, com prestações para cobertura de todas as eventualidades, entre 1990 e 2001 , em alguns países da UE - 25

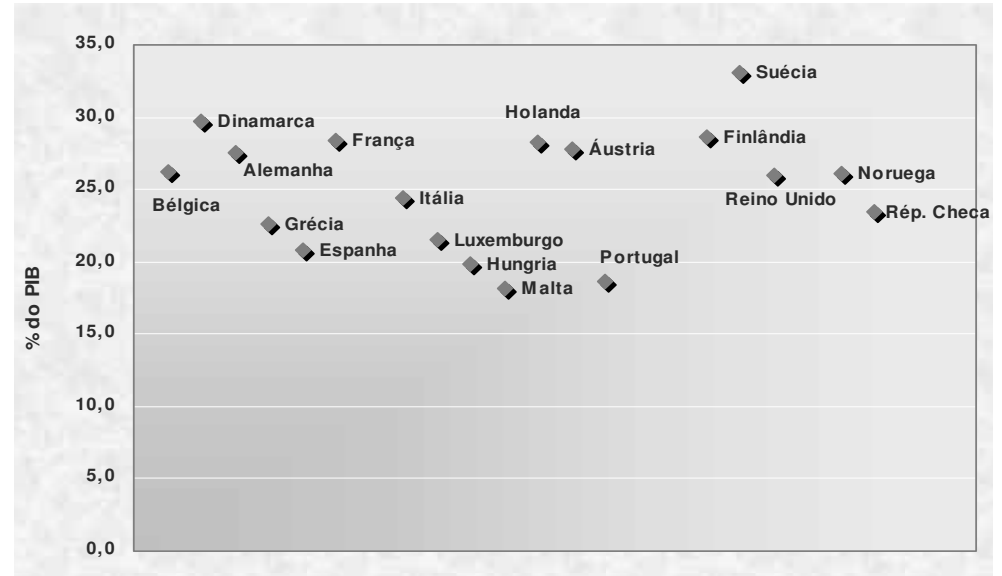

Fonte: EUROSTAT ${ }^{2}$

Gráfico $6 \triangleright$ Evolução das despesas com velhice em Portugal

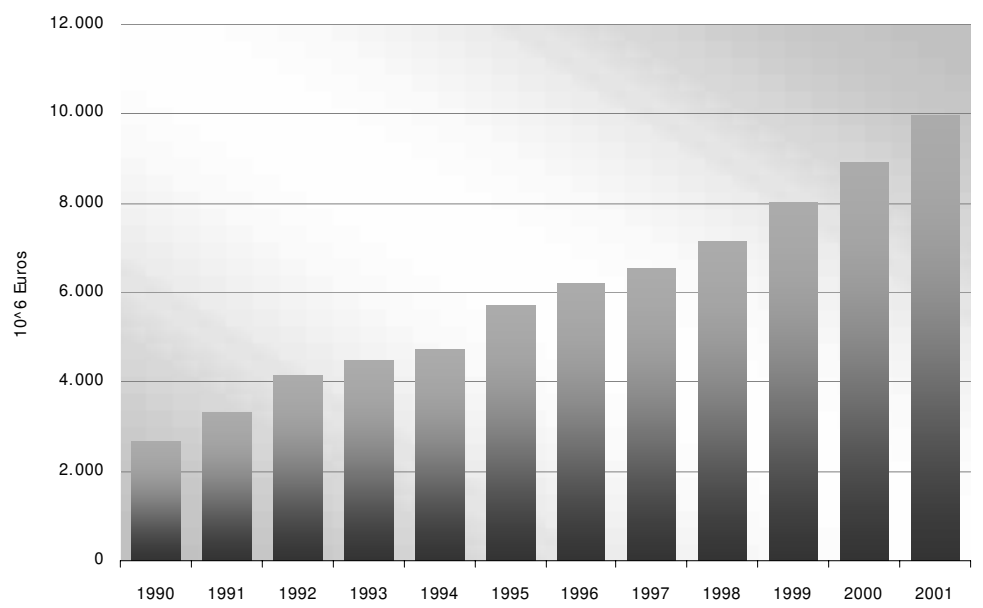

Fonte: EUROSTAT ${ }^{3}$

\section{Notas}

1 Vide Quadros 1, 2 e 3

2 Os valores referentes a alguns anos do período considerado para cálculo da média, para os diversos países, são resultantes de estimativas ou previsões do EUROSTAT

3 O valor referente ao ano 2001 resulta de previsão do EUROSTAT 